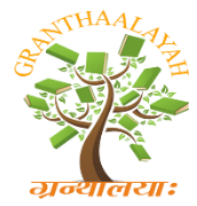

Science

\title{
DESIGN AND IMPLEMENTATION OF AN INTERACTIVE SYSTEM FOR ZOO APPLICATION USING SMART MOBILE PHONE AND QR CODE
}

\author{
Widad Kadhim *1, Prof. Dr. Salih M. Al-Qaraawi ${ }^{2}$ \\ ${ }^{* 1}$ Iraqi Commission for Computers and Informatics, Informatics Institute for Postgraduate \\ Studies, Iraq \\ ${ }^{2}$ Control and Systems Eng. Department, Computer Engineering, University of Technology, Iraq
}

\begin{abstract}
This paper presents an interactive application to be used in an important entertainment place visited by young, old and children on holidays and vacations to spend fun times. The system consists of the zoo's mobile application, quick response (QR) code technology as front end, and network system as back end. The mobile application helps the visitor to scan the QR tag that attached on each animal's cage to send the request to a network system that processes the request and returns the result to the visitor's mobile screen in the form either text or text to speech. on the other side, the network system consists of a network provider to provide services that enable the visitor's mobile to access the system and the main server which contains animal's information in three languages; English, Arabic and French. The system provides several capabilities, such as playing audio files stored in the server which contains the animal's voice. The visitor can also see a list of pets that the zoo administration has offered for sale where the visitor can buy any pet that he/she wants. The aim of this system is to facilitate the visitor's tour of the zoo by using modern technology to make the tour fun and non-routine.
\end{abstract}

Keywords: QR Code; Smart Mobile; Interactive System; Zoo Application; Text to Speech; Local Server.

Cite This Article: Widad Kadhim, and Prof. Dr. Salih M. Al-Qaraawi. (2020). "DESIGN AND IMPLEMENTATION OF AN INTERACTIVE SYSTEM FOR ZOO APPLICATION USING SMART MOBILE PHONE AND QR CODE." International Journal of Research Granthaalayah, 8(4), 285-296. https://doi.org/10.29121/granthaalayah.v8.i4.2020.68.

\section{Introduction}

Due to the great development in information technology and the widespread use of smart mobile devices in most areas of life, researchers always think about combining several aspects to be useful for human life [1]. There are a lot of mobile applications that have been used in many public institutions and places such as universities, libraries, museums and markets for the purpose of facilitating the work of these institutions. This can be summarized by reducing the time and efforts of their workers as well as meeting the needs of people entering these places and providing the 
services in an efficient manner[2],[3]. Several techniques have been used to develop and design these systems such as RFID, BARCODE and QR code[4]. The two dimensional barcode was invented in 1994 by Toyota Motors to tracks vehicles and parts during the manufacturing process [5].The $\mathrm{QR}$ code is a two-dimensional array that stores data both vertically and horizontally whereas the barcodes are parallel lines which stores the data in one dimension only[6]. In addition, the quick response code is characterized by its ability to correct errors because it contains four levels L,M,Q,H and Reed Solomon codes [7],[8].

\section{Literature Survey}

In 2012, D. Schön et al. [9] presented a quiz application for mobile and laptop devices. The implementation of this application was done as a web application and it was used for e-learning platform in the university by enabling the student's mobiles and laptops as voting devices and used dynamically generated Quick Response (QR) codes to establish the link between the devices and the platform.

In 2012, Li-Chuan et al. [10] implemented a management system at the hospital using QR codes to repair medical devices so that device or facility engineers can quickly get detailed device information and return medical devices to normal operation.

In 2013, D. Lorenzi et al. [11] presented a mobile platform used QR code for enhancing the services of government. The study proposed a system to integrate the QR code system with the corresponding smartphone application in two study cases for the National Park Services and the Mobile Environmental Information Services by focusing on the development of a QR code waypoint system for park navigation and encourage the use of parks in gamification.

At the same year, O. M. Arulogun et al. [12] proposed a system used RFID technique to solve recurrent lecture attendance monitoring problem to eliminate the time wasted during collecting manual attendance and the opportunity for education managers to get face-to-face classroom statistics and assign appropriate attendance scores and further administrative decisions. The students can fill their attendance simply by swiping or moving their ID card.

In 2014, K. Czuszynski and J. Ruminski [13] presented an application used in healthcare to exchange laboratory results from labs and patients, and between patients and electronic medical records. Mobile applications can be decoded, stored and encrypted information also conduct a preliminary study to provide eGlasses which is an electronic glass device that processes data from graphic patterns. Mobile phones used as electronic glasses simulators.

In 2015, P. Bhattacharjee et al. [14] presented a project using the Barcode to track vaccine by using the mobile phone to scan the barcode of vaccine package which used a Linked Data-based information system based on visualization and authentication. The system used WAMP Server to saving data (Apache, PHP, MySQL database) as a software framework with mobile application.

In 2017, B. Kumar and S. Kareemulla [15] suggested a mobile application that updates employee attendance using QR codes instead of manual login. The QR code printed on the ID card can be scanned by an application installed on the employee's smartphone. Also, a special software was 
installed on the company's server to perform the attendance calculations, so the employee's mobile need connecting to the Internet to send the data to the company's database.

In 2017, K. Pragna et al. [16] designed and implemented an embedded system to find the losing or the misplacing car keys by using QR code, Android application to scan the QR code, and mobile Bluetooth to car's keyless secure access. The system Provides keyless unlocking using a smartphone while maintaining security by providing security against unauthorized access to the car by using a three-level authentication in the lock/unlock process.

In 2019, G. Firmansyah and D. Hariyanto [17] presented a study aimed to produce modern teaching materials to improve the learning motivation that depends on the quick response code to facilitate the student access to course curricula easily, quickly and at the cheapest costs.

\section{The Proposed System Structure}

The proposed system constructed with four elements, as shown in Figure (1). These elements arranged in two ends: the front end designed with the QR code and the Android application while the back end designed with the network system which consists of network provider and the main server installed in a laptop, as illustrated in Figure (2).

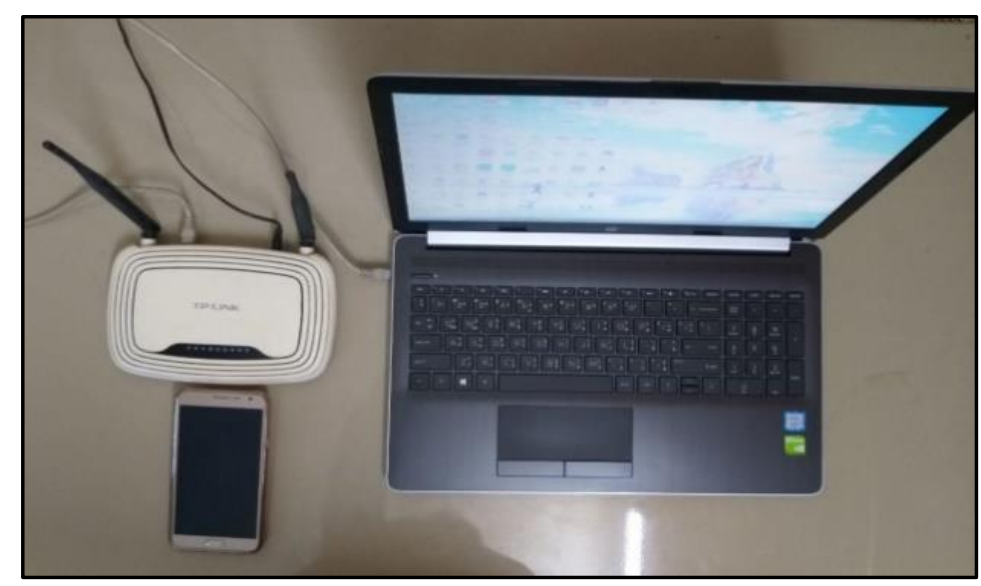

Figure 1: The elements of proposed system

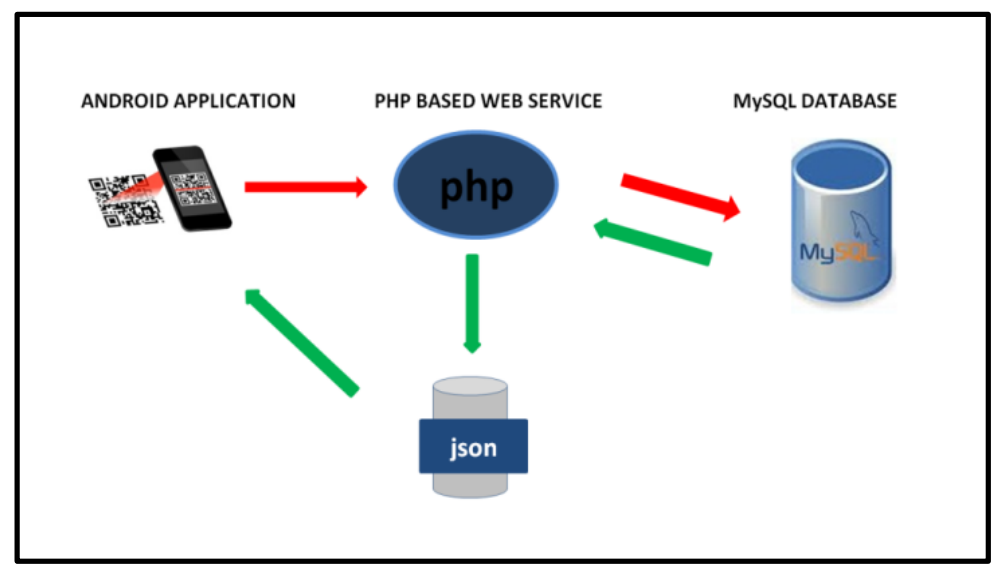

Figure 2: The structure of proposed system 


\subsection{The Front- End (Qr Code \& Mobile Application)}

\subsubsection{QR Code}

The QR code is characterized by its ability to store large amounts of data, as well as its speed and precision and its ability to correct errors [18]. In this paper the QR tag can be generated by online generator by using the name of the animal in three languages Arabic, English and French. As an example, the tag encoded by text "elephant" in the English language, as shown in Figure (3) and then attached on the cage of the animal to be scanned by the visitor's mobile camera.

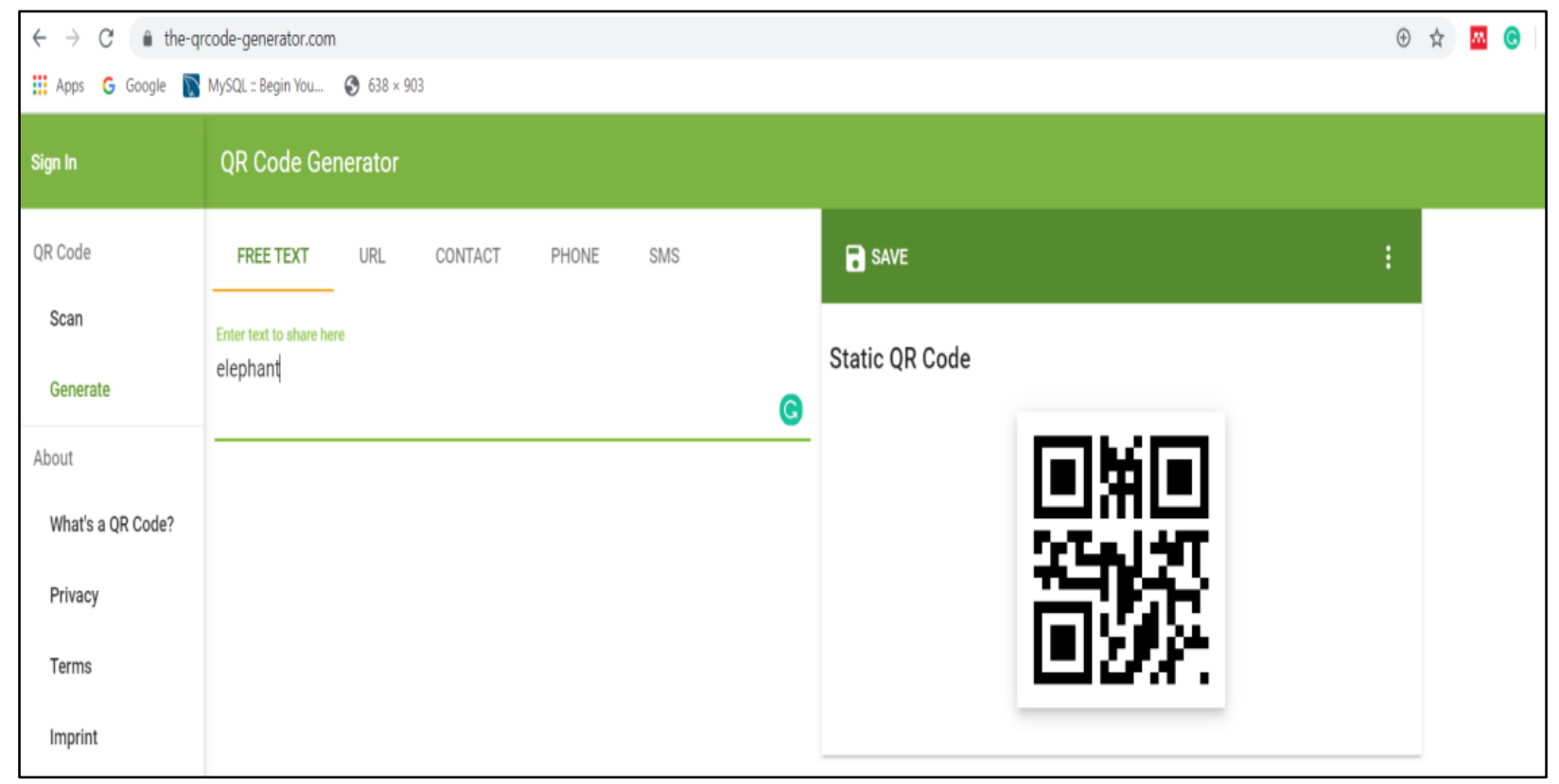

Figure 3: The QR code generation for "elephant"

\subsubsection{Mobile Application}

The mobile application of this system was programmed by Java Language using Android Studio IDE [19]. The mobile application in the proposed system facilitates the process of decoding the QR code with the help of a ZXING (pronounced "zebra crossing") library implemented in Java [20] and VOLLEY library [21] which are used to retrieve the data from the server in the textual form that can be heard as speech by text to speech feature if the visitor is a child and can't reading[22]. The application also presents playing the audio files that contain the animal sound and stored in the main server. In addition to the possibility of buying a pet from a pet exhibition in the zoo and the visitor can rating the application if he/she likes to do it. Figure (4) represents the block diagram of the complete proposal for zoo application and the sequences of taking a tour in the zoo. 


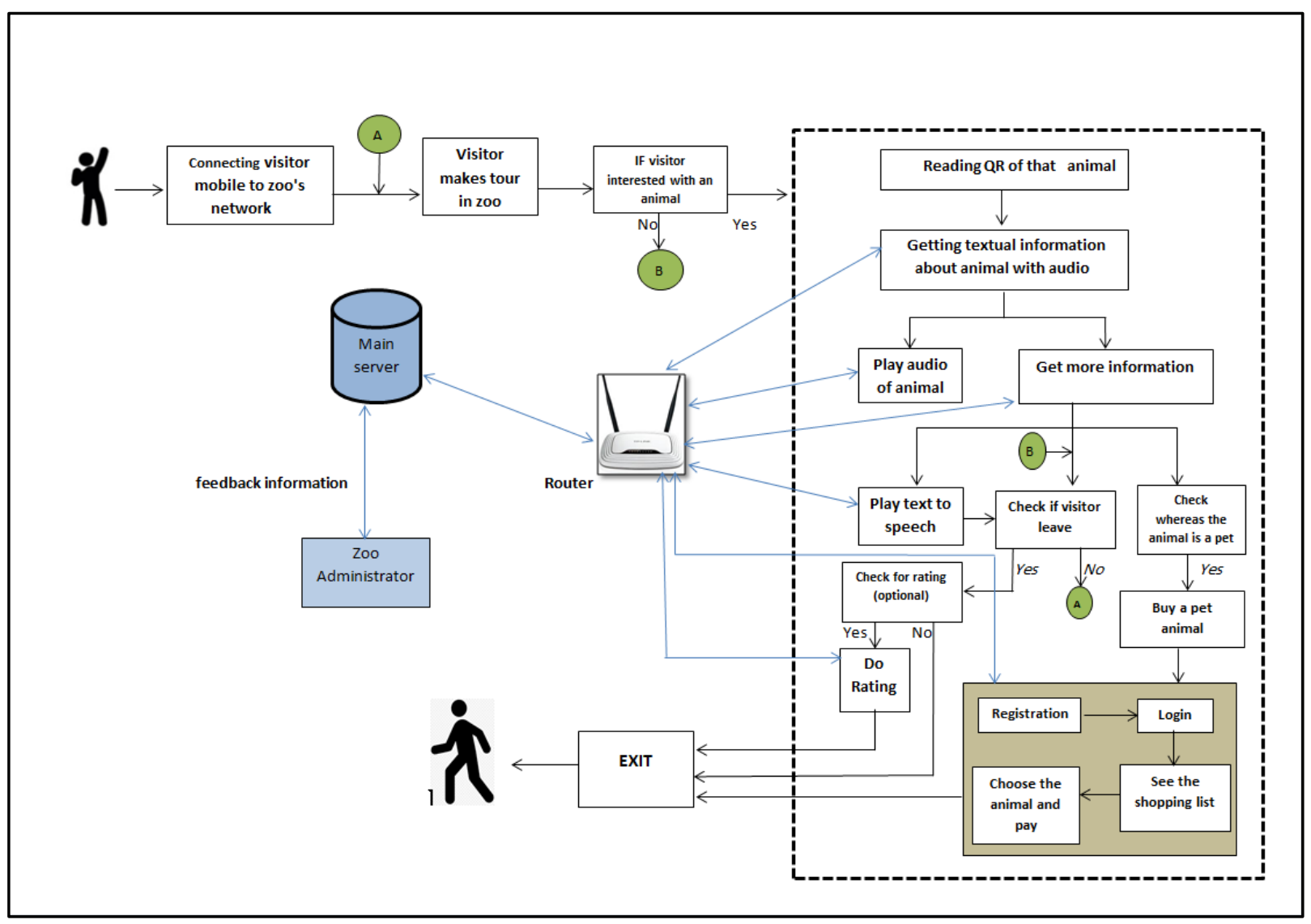

Figure 4: The block diagram of the proposed system

\subsection{The Back- End (The Network System)}

The network system consists of two parts, as shown below:

\section{Network Provider}

Mobile applications require faster and more stable network connections to meet the needs of mobile users for time-critical, immediate and efficient tasks. In this prototype system a router was used as network provider to all services inside the zoo that helps the system to working well[20].

\section{The Main Server}

The proposed system using XAMPP server (Apache, PHP, and MySQL on Windows 10)[24] installed in HP laptop for storing and hosting the data. The data for each animal at the zoo was stored in a MySQL database hosted on an Apache server, using PHP as the server-side scripting language. JSON parser for the mobile application was used to send data written to/from the database by the PHP script[25]. The information of each animal in the zoo was stored in the database in three tables each table written in different language such as: Arabic language, English language and French language, as shown in Figure (5). The data entered in the tables by using web page designed with PHP, HTML and CSS. These pages are used by administrator to create, read, update and delete (CRUD) operations in the database tables, as shown in Figure (6). 


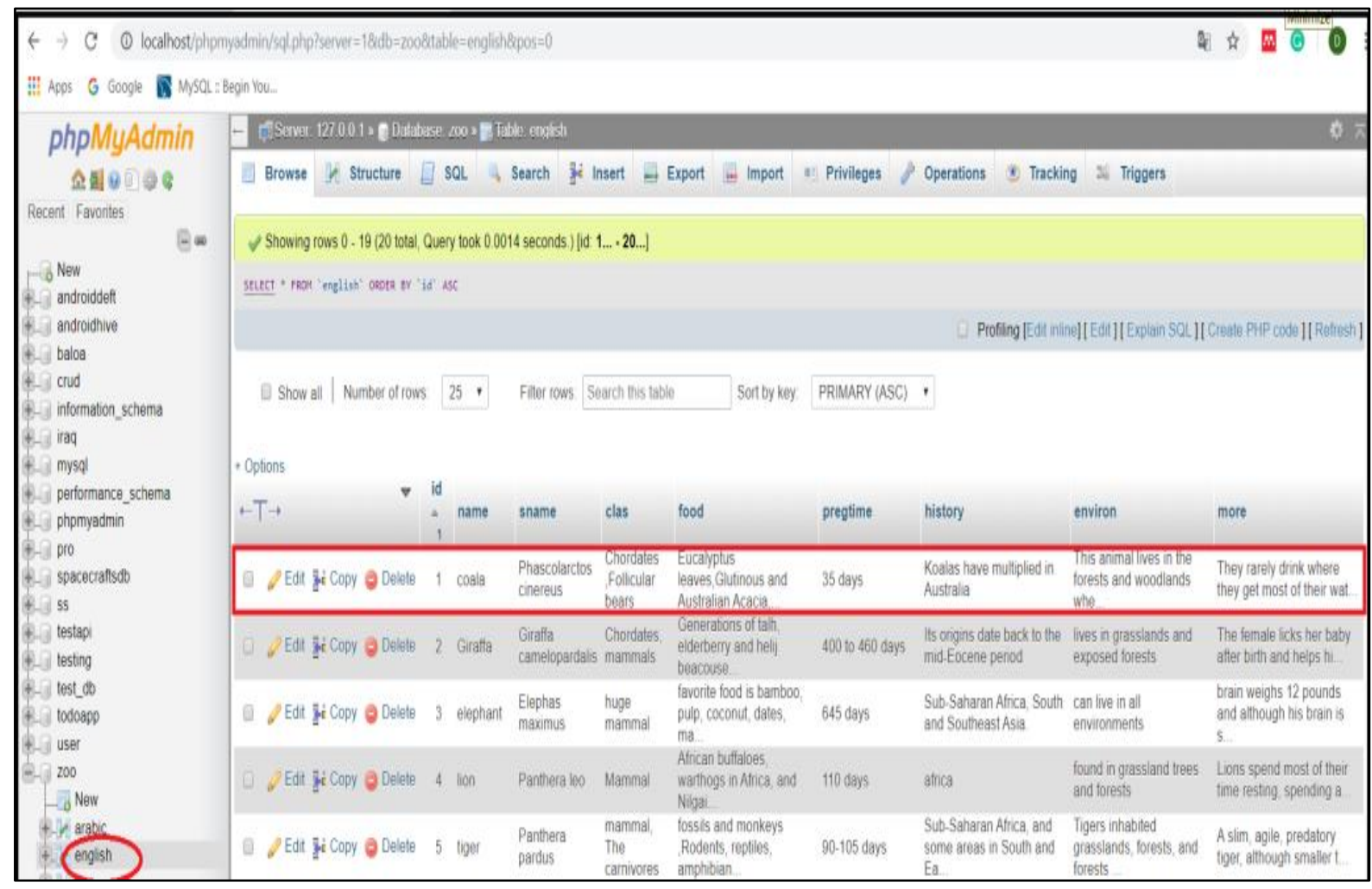

(a)

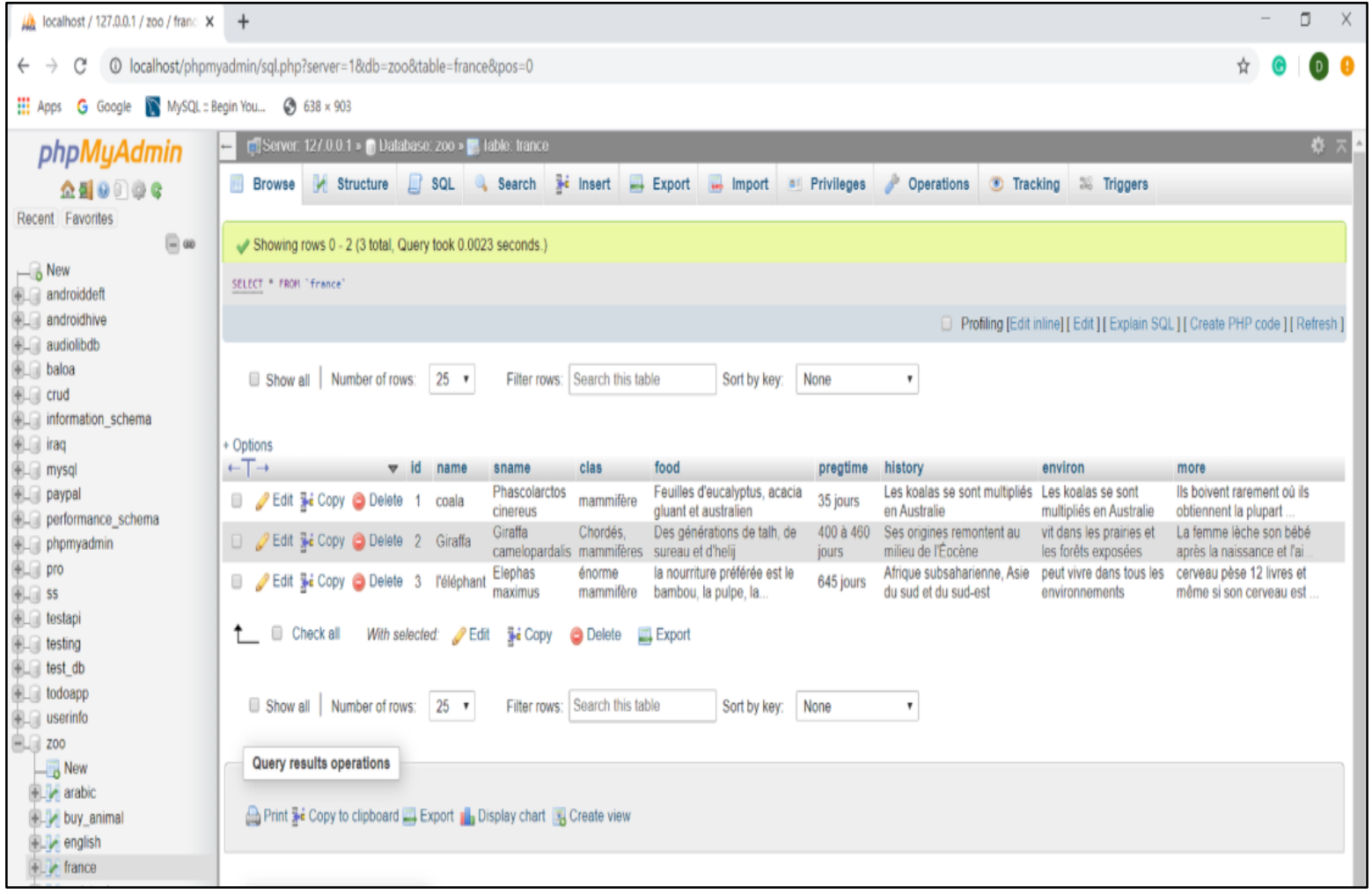

(b) 


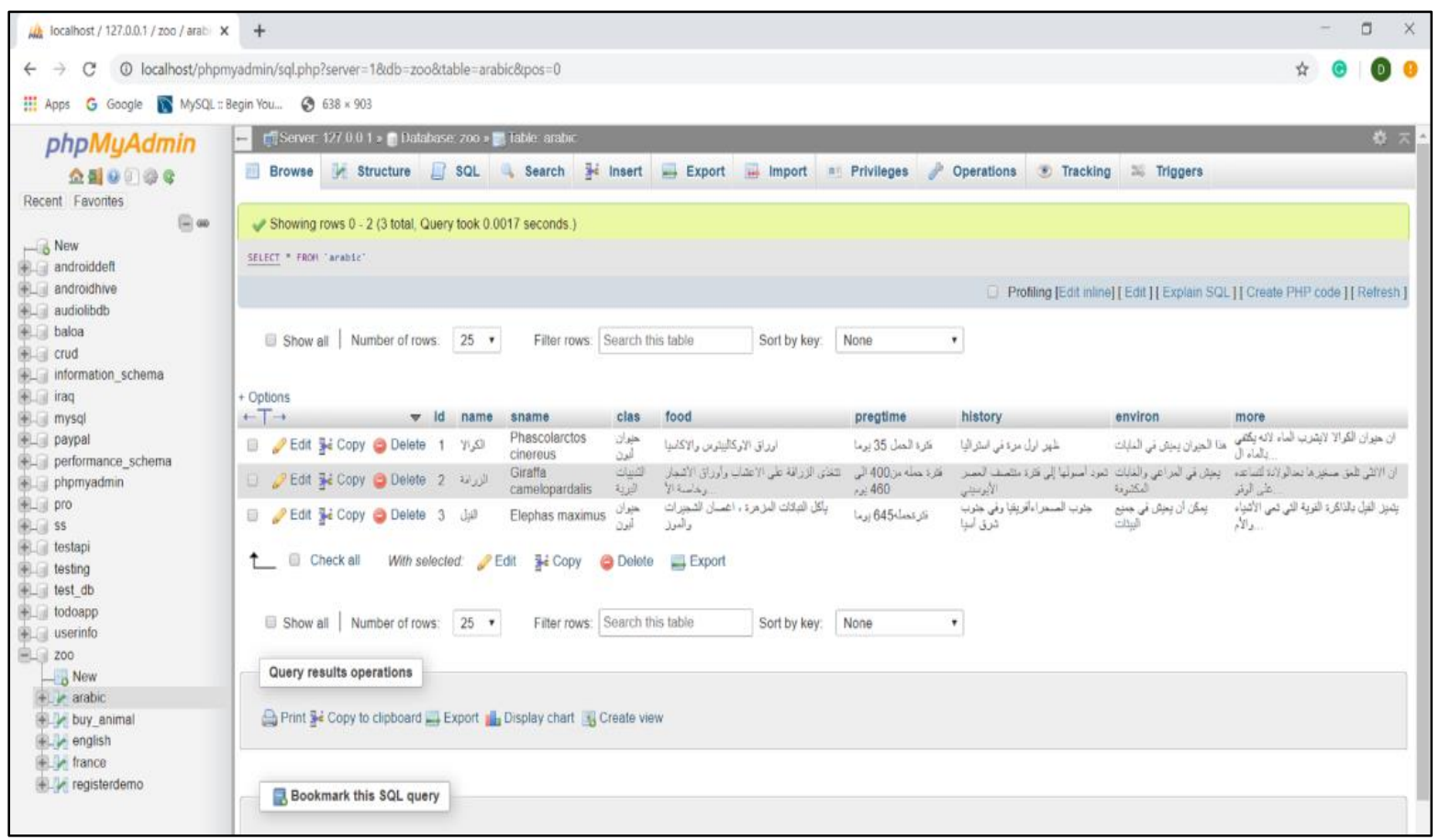

(c)

Figure 5: The information of animals in the database a- in English language b- in French language c- in Arabic language

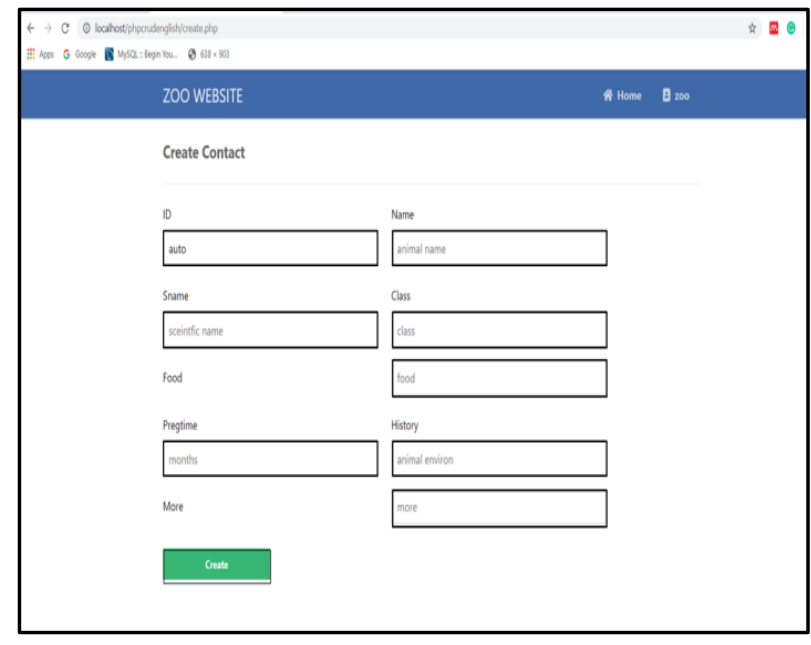

(a)

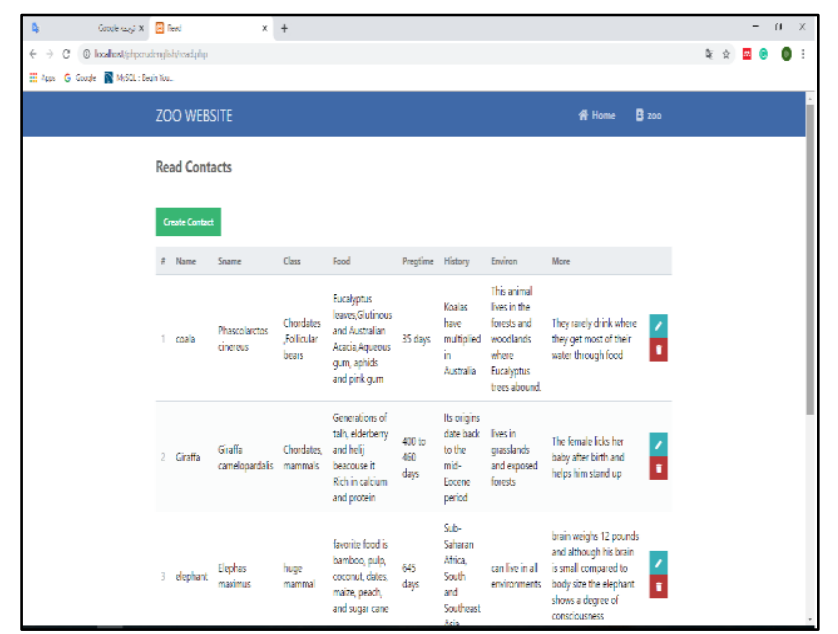

(b)

Figure 6: CRUD operations of data (a- create and read data $b$-update or delete data)

\section{Results and Evaluation}

\subsection{Connecting to Zoo's Network}

The visitor's mobile phone can be connected to the zoo's network when he/she enters the zoo gate and open the mobile application and press "connect to zoo network" button to get the name of 
network and the password also can check the network connection. When the "check network connection" button is clicked then the tour is starting, as shown in Figure (7).

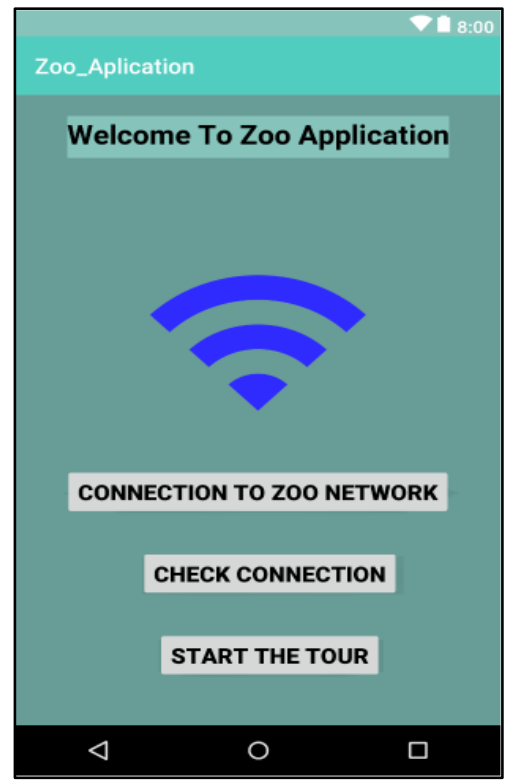

(a)

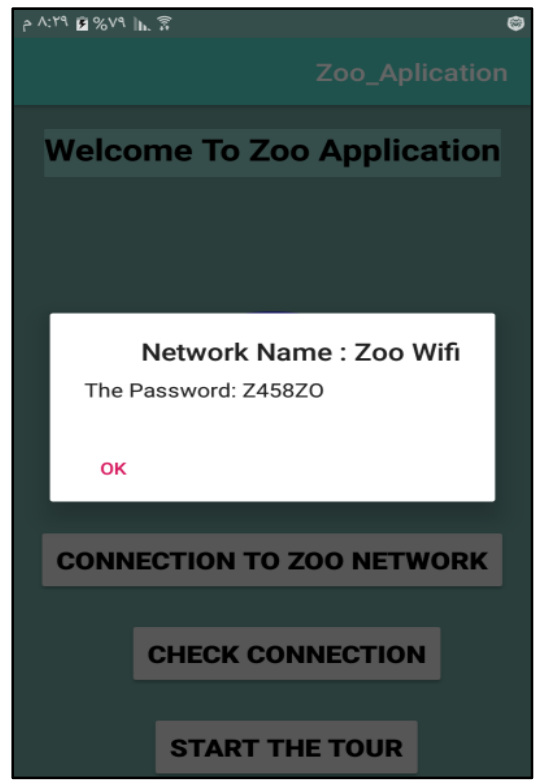

(b)

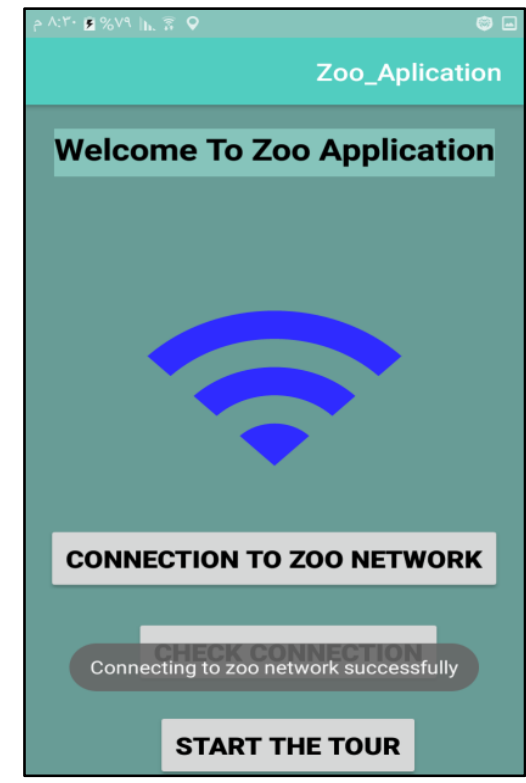

(c)

Figure 7: a-connecting to zoo's network b-the network name and password c- check connection

\subsection{Choose the Preferred Language}

After visitor's mobile is connected to the zoo's network and the visitor starts his/her tour in the zoo at the first, a list of languages appear which help the visitor to choose the preferred language from list of languages, as shown in Figure(8).

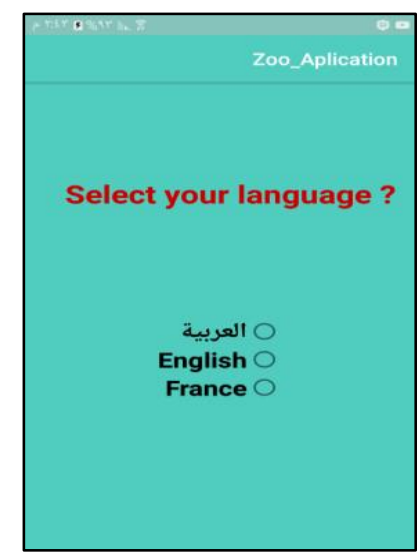

Figure 8: Language selection

\subsection{Scanning QR Tag and Get Brief Information}

After the visitor chooses the language the scanning process can be started by clicking "scan" button and the camera of visitor's mobile scanning the QR tag. Brief information of that animal will be displayed on visitor's mobile screen, as illustrated in Figure (9). 


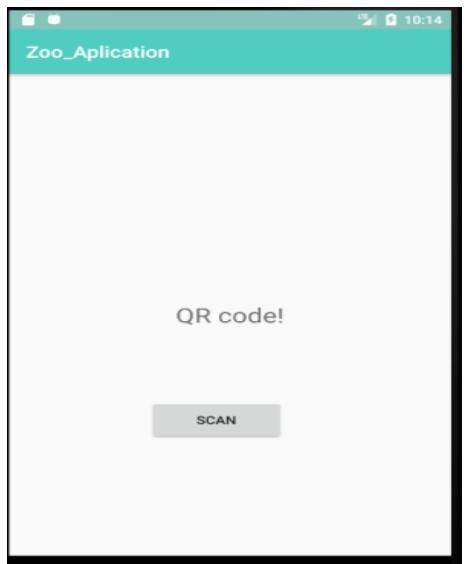

(a)

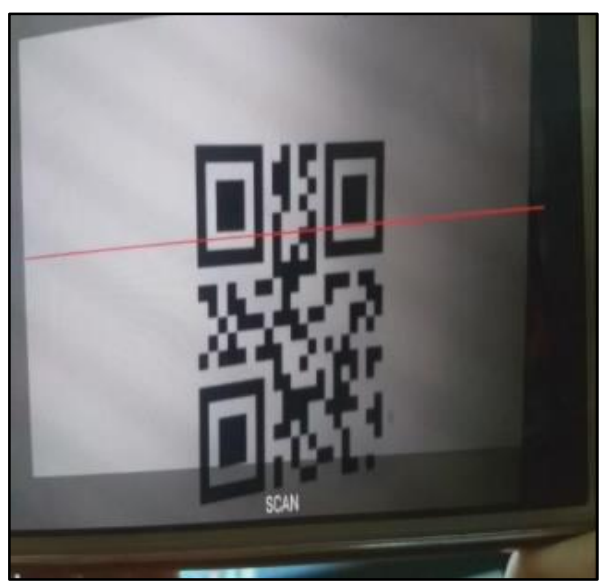

(b)

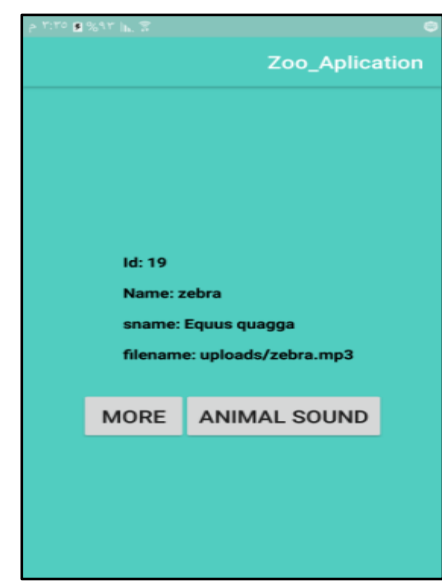

(c)

Figure 9: a-QR scanning button b- scanning process c- gets brief information

\subsection{Play Animal Sound and Get More Information}

The application has a capability to play audio file that contains the animal's sound when the visitor clicked on "animal sound" button. More information about the animal will be displayed when he/she clicked "more" button to show a text containing more information about that animal, as shown the Figure (10). Moreover, if the visitor is child can't read the text it can hear the speech when "text to speech" button is clicked.

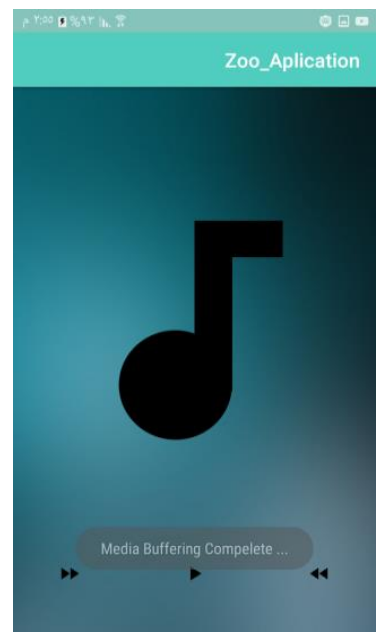

(a)

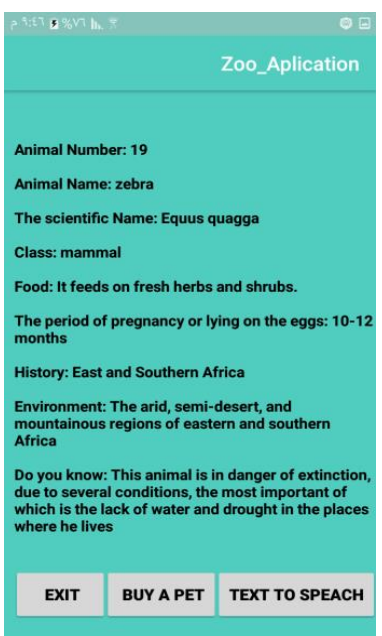

(b)

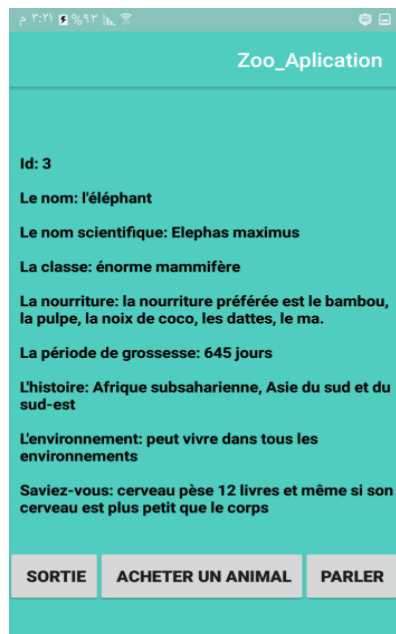

(c)

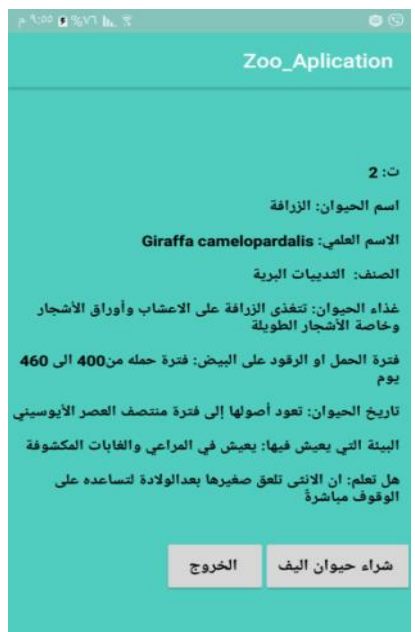

(d)

Figure 10: a- play the animal sound b-more information in English c- more information in French d- more information in Arabic

\subsection{Buy a Pet and Rating the Application}

The application gives the visitor the capability to purchase a pet from a list of pets after registration in the system, as illustrated in Figure (11). The system also provides the ability to rating the application and making a report by the administration of zoo's database when the zoo's management office needs any database report, as illustrated in Figure (12). 


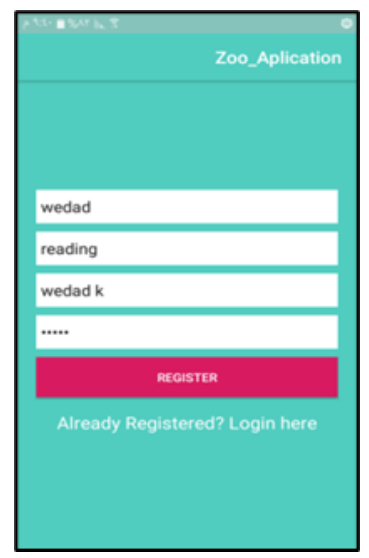

(a)

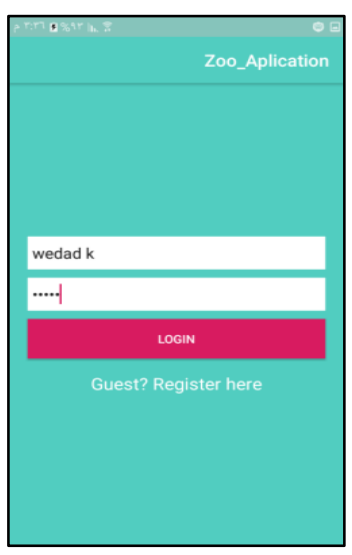

(b)

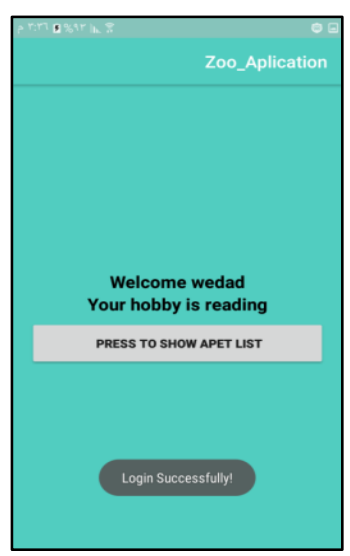

(c)

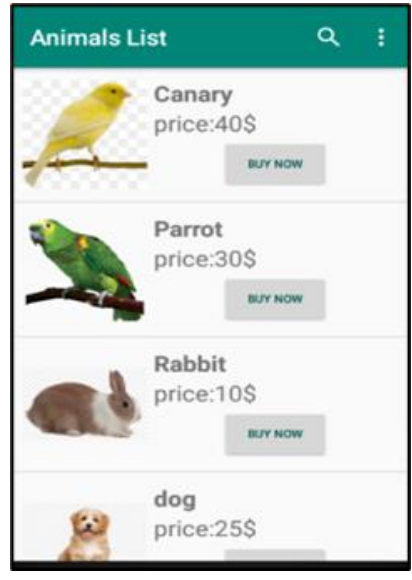

(d)

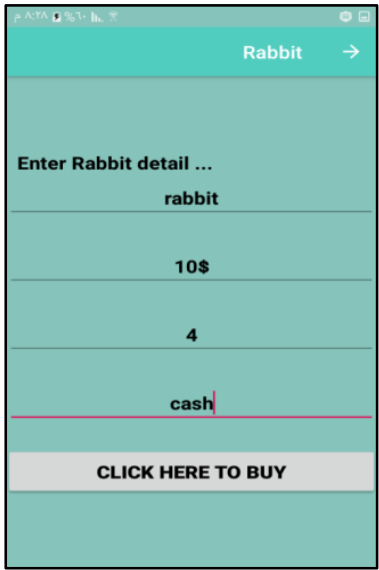

(e)

Figure 11: Buy a pet steps a- registration in the system, b- login to start, c- login successfully, d- animal list, e- buys the pet

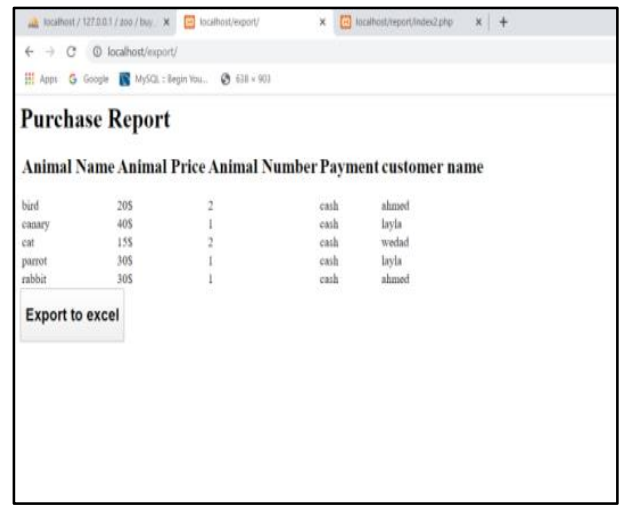

(a)

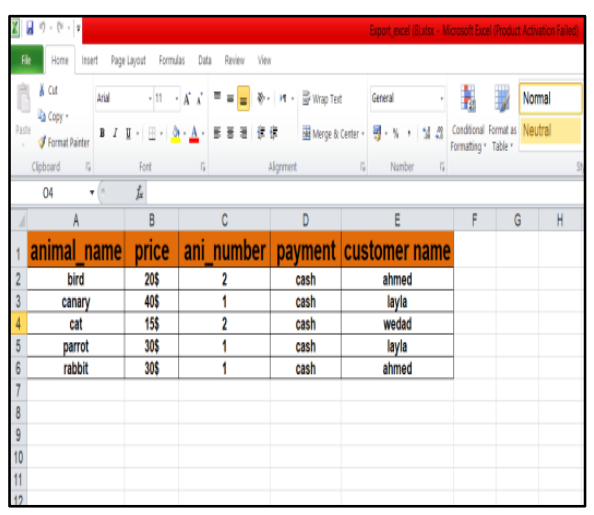

(b)

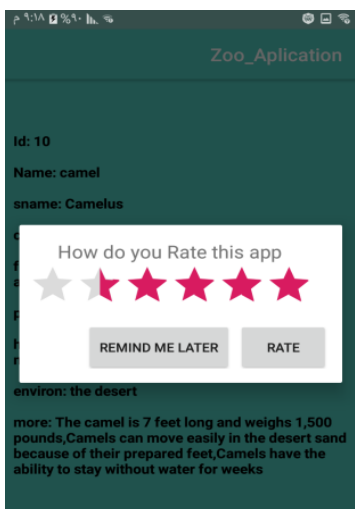

(c)

Figure 12: a- purchase report, b- the exported purchase report in excel, c- rating the application

\section{Conclusion}

The QR code has many benefits in various fields where because it has a quick response and a large amount of data that stored in, in addition to the ability to correct errors. So, it was used in the 
proposed zoo system with the mobile applications that scanned it and retrieve brief information or detailed information about any animal in the zoo as a text or text to speech from the main server. In addition, the ability to play an audio file that contains the animal sound which is stored in the main server database. The proposed system introduced also the possibility of buying a pet from a pet exhibition in the zoo. This system helps and facilitates the visitor's tour inside the zoo of all ages, different languages and cultures, as well as the exclusion of boredom and routine tours through the use of modern technology during the tour.

\section{References}

[1] M. Sarwar, T. R. Soomro, Impact of Smartphones on Society, Eur. J. Sci. Res., vol. 98, no. 2, 2013, 216-226.

[2] M. Pérez-Sanagustín, D. Parra, R. Verdugo, G. García-Galleguillos, M. Nussbaum, Using QR codes to increase user engagement in museum-like spaces, Comput. Human Behav., vol. 60, 2016, 73-85.

[3] S. A. Case, D. Bosco, C. Central, A. Pradesh, S. C. Singha, M. K. Verma, Integration of AIDC Technology in Mobile via QR Code for Enhancing the Library Services : A Case Study of Don Bosco College Central Library, Arunachal Pradesh, Indian J. Inf. Sources Serv., vol. 9, no. 2, June 2019, 44-48.

[4] J. P. Qian, X. T. Yang, X. M. Wu, L. Zhao, B. L. Fan, B. Xing, A traceability system incorporating 2D barcode and RFID technology for wheat flour mills, Comput. Electron. Agric., vol. 89, 2012, 76-8,.

[5] S. Wang, T. Yang, J. Li, B. Yao, Y. Zhang, Does a QR code must be black and white?, Proc. 2015 Int. Conf. Orange Technol. ICOT 201, 2016, 161-164.

[6] S. K. Sahu, S. K. Gonnade, QR Code and Application in India, Int. J. Recent Technol. Eng., vol. 2, no. 3, 2013, 26-28.

[7] Y. C. B, W. Susilo, G. Yang, J. G. Phillips, I. Pranata, A. M. Barmawi, Exploiting the Error Correction Mechanism in QR Codes for Secret Sharing, Springer Int. Publ. Switz., vol. 1, 2016, 409-425.

[8] M. B. Dissanayake, Y. Deng, A. Nallanathan, E. M. N. Ekanayake, M. Elkashlan, Reed Solomon Codes for Molecular Communication with a Full Absorption Receiver, IEEE Commun. Lett., vol. 21, no. 6, 2017, 1245-1248.

[9] D. Schön, M. Klinger, S. Kopf, and W. Effelsberg, "MobileQuiz - A Lecture Survey Tool using Smartphones and QR Tags," Int. J. Digit. Inf. Wirel. Commun., vol. 2, no. 3, 2012, 231-244.

[10] L. C. Chu, C. L. Lee, C. J. Wu, Applying QR code technology to facilitate hospital medical equipment repair management, Proc. - 2012 Int. Conf. Control Eng. Commun. Technol. ICCECT 2012, 856-859.

[11] D. Lorenzi, J. Vaidya, S. Chun, B. Shafiq, V. Atluri, Enhancing the government service experience through QR codes on mobile platforms, Gov. Inf. Q., vol. 31, no. 1, 2014, 6-16.

[12] O. M. Arulogun O. T., Olatunbosun, A., Fakolujo O. A., Olaniyi, RFID-Based Students Attendance Management System, Int. J. Sci. Eng. Res., vol. 4, no. July, 2013, 1-9.

[13] K. Czuszynski and J. Ruminski, "Interaction with medical data using QR-codes," Proc. - 2014 7th Int. Conf. Hum. Syst. Interact. HSI 2014, pp. 182-187, 2014.

[14] P. S. Bhattacharjee, M. Solanki, R. Bhattacharyya, I. Ehrenberg, S. Sarma, VacSeen: A linked databased information architecture to track vaccines using barcode scan authentication, CEUR Workshop Proc., vol. 1546, 2015, 39-48.

[15] B. D. Kumar, S. Kareemulla, Smart Mobile Attendance System for Employees Using QR Scanner, Asian J. Appl. Sci. Technol., vol. 1, no. 5, 2017, 35-39.

[16] K. P. L. Pragna P Rao, PushpaBai , Sneha, Qr Code for Safety and Security Applications, Int. J. Res. Eng. Technol., vol. 06, no. 06, 2017, 15-18. 
[17] G. Firmansyah, D. Hariyanto, Health and Sport QR Code Based Teaching Materials for Organizational Classes and Game Systems, Journal of Physical Education,vol. 6, no. 1, 2019, 610.

[18] H. L. Cai, B. Yan, N. Chen, J. S. Pan, H. M. Yang, Beautified QR code with high storage capacity using sequential module modulation, Springer, vol.06, April 2019, 15-18.

[19] C. P. Rahul Raj, S. B. Tolety, A study on approaches to build cross-platform mobile applications and criteria to select appropriate approach, 2012 Annu. IEEE India Conf. INDICON 2012, 625629.

[20] A. A. D. Octavian DOSPINESCU, From Local Data to Global Information Using Zxing Library in Android, The 6th International Conference on Globalization and Higher Education in Economics and Business Administration - GEBA 2012, 538-542.

[21] Y. Shulin, H. Jieping, Research and implementation of Web Services in Android network communication framework Volley, IEEE Commun., 2014, 1-3.

[22] V. Hanumante, R. Debnath, D. Bhattacharjee, D. Tripathi, S. Roy, English Text to Multilingual Speech Translator Using Android, Int. J. Inven. Eng. Sci., vol. 2, no. 5, 2014, 4-9.

[23] T. N. Quach, P. Thaichon, C. Jebarajakirthy, Internet service providers' service quality and its effect on customer loyalty of different usage patterns, J. Retail. Consum. Serv., vol. 29, 2016, 104113.

[24] R. Nandal, A Research Paper OnWebsite Development Optimization Using Xampp / PHP, Int. J. Adv. Res. Comput. Sci., vol. 8, no. 5, 2017, 1231-1235.

[25] G. Wang, Improving data transmission in web applications via the translation between XML and JSON, Proc. - 2011 3rd Int. Conf. Commun. Mob. Comput. C. 2011, 182-185.

*Corresponding author.

E-mail address: widadalsaedy@gmail.com/drsalihalqaraawi@gmail.com 